University of Windsor

Scholarship at UWindsor

\title{
The effects of inbreeding on sperm quality traits in captive-bred lake trout, Salvelinus namaycush (Walbaum, 1972)
}

K. Johnson

Ian A.E. Butts

J. L. Smith

C. C. Wilson

Trevor E. Pitcher

University of Windsor

Follow this and additional works at: https://scholar.uwindsor.ca/glierpub

Part of the Biochemistry, Biophysics, and Structural Biology Commons, and the Physical Sciences and Mathematics Commons

\section{Recommended Citation}

Johnson, K.; Butts, Ian A.E.; Smith, J. L.; Wilson, C. C.; and Pitcher, Trevor E.. (2015). The effects of inbreeding on sperm quality traits in captive-bred lake trout, Salvelinus namaycush (Walbaum, 1972). Journal of Applied Ichthyology, 31, 62-70.

https://scholar.uwindsor.ca/glierpub/110

This Article is brought to you for free and open access by the Great Lakes Institute for Environmental Research at Scholarship at UWindsor. It has been accepted for inclusion in Great Lakes Institute for Environmental Research Publications by an authorized administrator of Scholarship at UWindsor. For more information, please contact scholarship@uwindsor.ca. 


\title{
The effects of inbreeding on sperm quality traits in captive-bred lake trout, Salvelinus namaycush (Walbaum, 1972)
}

\author{
By K. Johnson ${ }^{1}$, I. A. E. Butts ${ }^{2}$, J. L. Smith ${ }^{1}$, C. C. Wilson ${ }^{3}$ and T. E. Pitcher ${ }^{1,4}$ \\ ${ }^{1}$ Department of Biological Sciences, University of Windsor, Windsor, ON, Canada; ${ }^{2}$ DTU Aqua, National Institute of Aquatic \\ Resources, Section for Marine Ecology, Technical University of Denmark, Charlottenlund Slot, Charlottenlund, Denmark; \\ ${ }^{3}$ Aquatic Research and Monitoring Section, Ontario Ministry of Natural Resources and Forestry, Trent University, \\ Peterborough, ON, Canada; ${ }^{4}$ Great Lakes Institute for Environmental Research, University of Windsor, Windsor, ON, Canada
}

\begin{abstract}
Summary
The effects of inbreeding in both captive and wild-caught species and populations have been reported to affect a wide variety of life history traits. Recently, the effects of inbreeding on reproductive traits such as sperm quality have become a subject of particular interest for conservation biology, evolutionary ecology, and management of captive populations. This study investigated the effects of inbreeding on sperm quality in a captive population of experimentally inbred and outbred lake trout, Salvelinus namaycush. It was found for moderately to highly inbred males (males with half-sib and full-sib parents, respectively), that sperm quality traits (velocity, motility, linearity, longevity, spermatocrit and morphology) showed no apparent inbreeding depression. The apparent lack of inbreeding effects on sperm quality traits may be due to several factors including (i) no inbreeding depression in the studied population, due to purging, low levels of inbreeding or lack of detection at the gametic level, or (ii) relaxed selective pressures due to benign hatchery conditions. The present study provides significant insight into the effects of inbreeding on sperm quality in a captive-bred salmonid population, and has important implications for hatchery rehabilitation programs for this species.
\end{abstract}

\section{Introduction}

Inbreeding, defined as the mating between relatives, can reduce the fitness of individuals across a wide variety of species. A reduction in fitness (or phenotype value in practical terms) of offspring from matings between related individuals compared to the fitness of offspring from randomly mated individuals is known as inbreeding depression (Wright, 1977; Charlesworth and Charlesworth, 1999). Two hypotheses (dominance and overdominance) have been posited to explain potential genetic mechanisms for inbreeding depression (Wright, 1977). Under the dominance hypothesis, inbreeding results in an increase in homozygosity, which in turn leads to the unmasking of deleterious recessive alleles that reduce fitness (Charlesworth and Charlesworth, 1999). The overdominance hypothesis states that an increase in homozygosity leads to reductions in fitness of inbred individuals at loci where heterozygotes had a selective advantage over homozygotes (Charlesworth and Charlesworth, 1999). Overall, reduced fitness due to inbreeding is likely a combination of both of these mechanisms, which can be difficult to distinguish (Keller and Waller, 2002). Across species, reduced fitness as a result of inbreeding has been reported in both captive and wild populations (Lacy et al., 1993; Crnokrak and Roff, 1999; Keller and Waller, 2002). Fitness losses associated with inbreeding are caused by a number of factors including increased parasite susceptibility (Rijks et al., 2008), growth deformities (Grant and Grant, 1995), decreased survivorship (Jiménez et al., 1994), and reduced fertility (Chen, 1993). As an individual's fitness is contingent on both their survival to sexual maturity and their subsequent reproductive success (Stearns, 1992), inbreeding depression can pose a serious threat to the viability of populations (Hedrick and Kalinowski, 2000; Wang et al., 2002).

Inbreeding depression has primarily been studied in traits that are closely linked to survival and/or reproduction (Crnokrak and Roff, 1999; Saccheri et al., 2005). Although the primary focus of many studies has typically been to look at reproductive traits such as mating success (Joron and Brakefield, 2003) and fertility (Johnston, 1992), inbreeding depression has also been shown to affect fitness in more cryptic ways, such as reduced sperm quality (Fitzpatrick and Evans, 2009). This phenomenon has been shown in both wild rabbits (Oryctoloagus cuniculus) and lions (Pantheo leo), for example, where decreased levels of heterozygosity were associated with increased levels of sperm abnormalities (Wildt et al., 1987; Gage et al., 2006). Inbreeding depression has also been shown to affect sperm performance traits such as motility and velocity, which are important determinants of fertilization success in many species (Fitzpatrick and Evans, 2009). It has been suggested that the associated decrease in sperm performance traits with inbreeding is mediated by sperm abnormalities due to DNA damage (Ruiz-Lopez et al., 2010). In white-footed mice (Peromyscus leucopus noveboracensis) and Mexican gray wolves (Canis lupus baileyi), an increase in inbreeding led to significant reductions in sperm motility (Asa et al., 2007; Malo et al., 2010), while in Florida panthers (Felis concolor coryi) sperm concentration and motility were both significantly lower compared to noninbred panther populations (Barone et al., 1994). It is 
thought that sperm may be particularly susceptible to the effects of inbreeding depression given the complex nature of spermatogenesis and the high potential for mutational defects (Gage et al., 2006). Given that sperm quality is indirectly related to fitness, it becomes an important mechanism influencing reproductive traits that have been affected by inbreeding, such as reductions in fertilization success (Gage et al., 2006). The majority of studies that have investigated the effects of inbreeding on sperm quality have focused on mammals; by contrast, studies on other taxa have been largely ignored (but see Zajitschek et al., 2009; Zajitschek and Brooks, 2010).

Lake trout (Salvelinus namaycush) is an interesting species to study the effects of inbreeding depression due to its unique life history and reproductive behaviour compared to other salmonids. Unlike most salmonids, lake trout are a longlived iteroparous species that have a tendency to breed nocturnally (Gunn, 1995). As a result, lake trout lack sexual dimorphism and little to no overt male-male competition exists (Gunn, 1995; Esteve et al., 2008). Given these unique traits, it is possible for sexual selection to be most effective at the gamete level in this species. In addition, lake trout populations in the Laurentian Great Lakes suffered major declines throughout the 1940 and 1950s as a result of overfishing, predation by the invasive sea lamprey (Petromyzon marinus), and habitat degradation (Walters et al., 1980; Selgeby et al., 1995). Since then, rehabilitation efforts have relied heavily on stocking fish from hatchery broodstocks that were founded from remnant Great Lakes populations (Guinand et al., 2003) but may be vulnerable to hatchery rearing practices and inadvertent population-level inbreeding (Miller and Kapuscinski, 2003).

In this study, we looked at whether inbreeding affects sperm quality in a captive-bred population of lake trout. To test this hypothesis, we compared sperm quality metrics of mature male progeny from four mating categories examining inbreeding in lake trout: (i) full-sib matings, (ii) maternal and (iii) paternal half-sib matings, and (iv) unrelated adults.

\section{Materials and methods}

\section{Creation of family lines}

The lake trout in this study originated from wild spawn collections from a native population in two interconnected lakes in Haliburton, Ontario (Clean and Macdonald lakes, lat. 45.2501; long. -78.5329). In 1983, wild fish were manually spawned $[10$ single-pair crosses $(10$ males and 10 females)] to establish 10 presumably unrelated families for studies in captivity. All families were reared at the Ontario Ministry of Natural Resources Codrington Fisheries Research Facility, located in Codrington, Ontario (lat. 44.1468; long. -77.8045). All fish at the hatchery were freeze-branded and fin clipped to allow for individual and family identification. In 1994, once males and females were sexually mature, four unrelated offspring from the singlepair crosses (two males and two females) were chosen haphazardly and used to set up a $2 \times 2$ full-factorial cross, producing four unrelated families (Fig. 1a). In 2003, the mature adults from these four families were used to create experimental inbreeding crosses. A full-factorial cross with eight females and four males was used to create 32 families, each exhibiting four levels of inbreeding based on mating parents that were: (i) full siblings, (ii) maternal half-siblings, (iii) paternal half-siblings and (iv) unrelated individuals (Fig. 1b). On 9 and 10 November 2009, 102 males from the 32 families were sampled for milt. Data has shown that sperm quality (i.e. motility, velocity, linearity, longevity, and spermatocrit) tends to peak in the middle of the spawning season (early November to early December; Johnson et al., 2013), therefore we can exclude any seasonal effects on sperm quality in this study.

\section{Fish husbandry and sperm collection}

Individuals were housed in five circular tanks ( 5 ' diameter with a working depth of 24") fed by untreated water from the headwaters of Marsh Creek (lat.: 44.1834; long.: -77.7828) and kept under a natural photoperiod and temperature regime. Males and females in each tank were prevented from mating by a lack of natural substrate on the bottom (Yeates et al., 2007). Fish were fed AquaBrood feed (7.5 mm pellet; Corey Nutrition Company, Fredericton, NB, Canada) at $0.5 \%$ body weight per day. Total length and weight (mean \pm SEM) of the males at the onset of spawning were $539.9 \pm 3.8 \mathrm{~mm}$ and $1697.1 \pm 36.7 \mathrm{~g}$, respectively. Males were anaesthetized using a $40-50 \mathrm{ppm}$ solution of MS-222 (Syndel International, Vancouver, BC, Canada). Milt samples were collected, using slight pressure to the abdomen (after the genital papilla was dried) and massaging towards the urogenital pore, in $532 \mathrm{ml}$ Whirl-Pak $($, plastic bags (Nasco, Newmarket, ON, Canada) and stored in a cooler $\sim 8^{\circ} \mathrm{C}$. Extra care was taken to ensure that urine, feces, blood, or freshwater did not contaminate the milt samples.

\section{Sperm activity}

Sperm were video-recorded using a CCD black and white video camera (XC-ST50, Sony, Japan) module at $50 \mathrm{~Hz}$ vertical frequency, mounted on an external-phase contrast microscope (CX41 Olympus, Melville, NY) with a $10 \times$ negative-phase magnification objective (Pitcher et al., 2009). Sperm performance traits (velocity, motility, linearity, and longevity) were assessed within $3 \mathrm{~h}$ of collection, by activating an aliquot $(<0.2 \mu \mathrm{l})$ of pure milt with $10 \mu \mathrm{l}$ of source water circulating through the hatchery. Water temperature was maintained by holding water samples in a cooler at $\sim 8^{\circ} \mathrm{C}$; which was the temperature of the water on 9 and 10 November 2009. Once video recordings were taken (in duplicate), sperm traits were analyzed, using the HTM-CEROS sperm analysis system (v. 12, CEROS; Hamilton Thorne Biosciences, Beverly, MA) set at the following parameters: number of frames $=60, \quad$ minimum $\quad$ contrast $=11$, photometer $=55-65$, minimum cell size $=3$ pixels. Sperm velocity, motility and linearity were recorded at 5 and $10 \mathrm{~s}$ post-activation. Sperm velocity was estimated as the average velocity measured over the actual point-to-track followed by the cell (i.e. curvilinear velocity, VCL). Sperm motility was calculated as the percentage of motile cells divided by the 


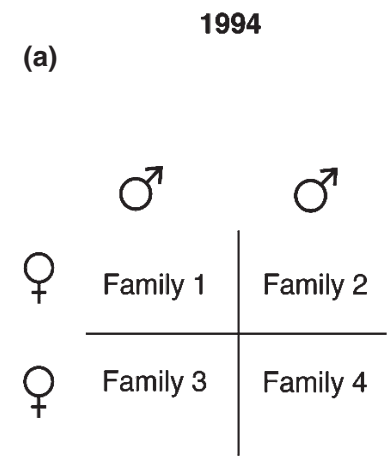

(b)
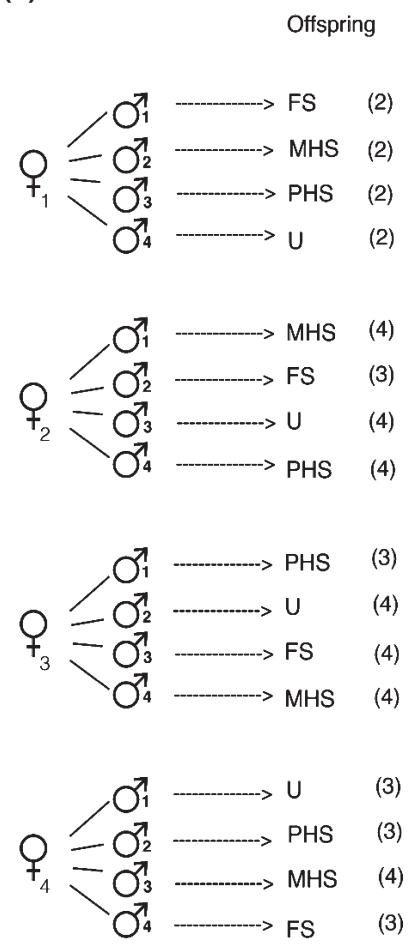

FS - Full Sibling Offspring MHS - Maternal Half Sibling Offspring
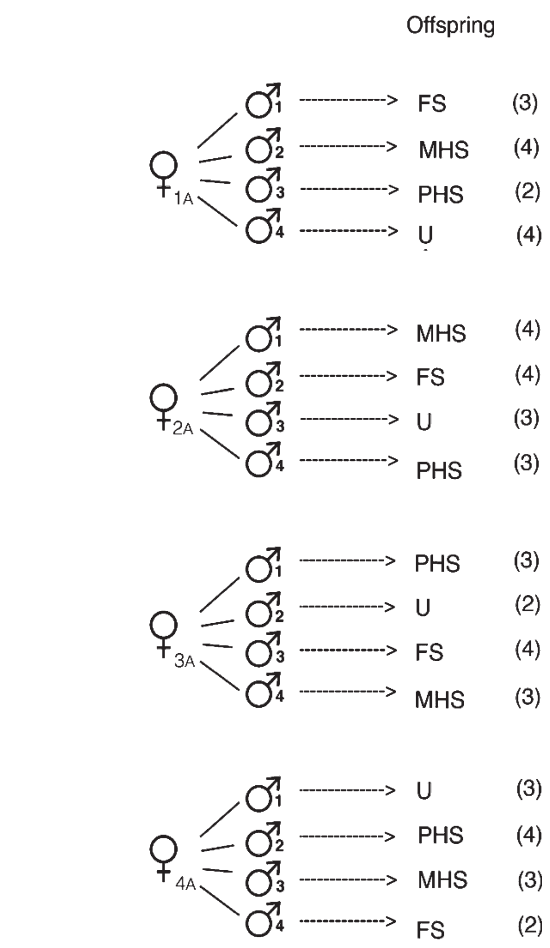

2003

PHS - Paternal Half Sibling Offspring U - Unrelated Offspring

Fig. 1. Breeding history of experimental population. (a) In 1994, four lake trout (Salvelinus namaycush) (two males and two females) were used to set up a $2 \times 2$ factorial cross, producing four families. (b) Sexually mature offspring from the $2 \times 2$ cross were used to set up experimental inbreeding crosses in 2003. Eight individual females were mated to the same four same males to produce matings between full sibs (FS), maternal half sibs (MHS), paternal half sibs (PHS) and unrelated individuals (U). Subscript numbers = female family origin (family 1, 2,3 or 4 ) and subscript letters = different females, same family. Numbers in brackets $=$ number of mature males from each family assessed for sperm quality traits

total number of cells. Sperm path linearity, which is the straightness with which a sperm cell moves per unit of distance traveled, was measured as the departure of the cell track from a straight line (i.e. VSL/VCL). Straighter swimming sperm will have a higher linearity value. Longevity was estimated as the time for $\sim 95 \%$ of the sperm cells to become immotile (Gage et al., 2004). The CASA system uses the average number of sperm per recorded track to estimate sperm performance traits. Each track was manually checked for quality control. If too few sperm were observed or if sperm were not properly recorded within the desired time frame ( $>5 \mathrm{~s}$ after the starting of video recording) tracks were removed from subsequent analyses.

\section{Spermatocrit}

Spermatocrit was estimated by adding milt $(250-1000 \mu \mathrm{l})$, for each male, into a $1500 \mu \mathrm{l}$ eppendorf tube. The tubes were then centrifuged for $10 \mathrm{~min}$ at $7500 \mathrm{~g}$ (accuSpin Micro 17; Fisher Scientific, Fair Lawn, NJ). Centrifuging milt separates sperm and seminal plasma into opaque white and clear solutions, respectively (Hoysak and Liley, 2001). To calculate spermatocrit, the volume of the opaque layer was recoded for each sample and then divided by total milt volume and expressed as a percentage.

\section{Sperm morphology}

Milt was collected from a subset of males $(\mathrm{n}=58 ; 12$ full sibs, 11 maternal half-sibs, 18 paternal half-sibs and 17 unrelated males). Milt samples $(1.5 \mu \mathrm{l})$ were preserved in $250 \mu \mathrm{l}$ of Courtland's saline solution with $2.5 \%$ glutaraldehyde. Three sperm morphology smears for each male were made by aliquotting $5 \mu \mathrm{l}$ of the preserved sperm onto a slide and smearing the cells using a separate slide, followed by a $10 \mathrm{~s}$ air drying period. The slides were stained using a Kwik-Diff тм staining kit (Thermo Fisher Scientific, Kalamazoo, MI). The staining protocol was modified from methods developed by Tuset et al. (2008) so that each slide was fixed for $5 \mathrm{~min}$ instead of the manufacturer's recommendation of five $\times 1 \mathrm{~s}$ dips. Slides were then rinsed in distilled water and allowed to air-dry for $24 \mathrm{~h}$. All slides were 
permanently sealed with a coverslip using $\sim 150 \mu$ l of Permount mounting medium (Fisher Scientific Company, Ottawa, Ontario, Canada). Slides were observed at $40 \times$ (tails) and $100 \times$ (heads) magnification under oil immersion using an Olympus BX52 microscope (Fig. 2a). Sperm head and tail images were captured using an Olympus DP72 digital camera and later analyzed using an ImageJ plug-in (Fig. 2b) (Butts et al., 2011). Sperm heads (mean $\pm \mathrm{SEM}=70 \pm 3$ per male) were measured for length and width, while flagella (mean \pm SEM $=29 \pm 4$ per male) were measured for length.

\section{Statistical analyses}

One-way ANOva models were used to compare Fulton's condition factor of adult males $[K=$ adult mass/(total length $\left.)^{3} \times 10000\right]$, sperm activity traits, spermatocrit, and sperm morphology between the levels of inbreeding. Sperm velocity, motility and linearity were analyzed at $5 \mathrm{~s}$ post-activation (Butts et al., 2012; Galvano et al., 2013). It has been shown in salmonids that once sperm is released and activated, there is $\sim 5 \mathrm{~s}$ to fertilize eggs (Hoysak and Liley, 2001). Therefore, a post-activation time of $5 \mathrm{~s}$ is the most biologically relevant as it corresponds to conditions found in the wild. All traits were tested for normality using the Shapiro-Wilk test and homogeneity of variances using Levene's test. Motility data were arcsine square root transformed. Due to violations of ANOVA assumptions, a Kruskal-Wallis non-parametric test was used to analyze Fulton's $K$, longevity, and spermatocrit. In the event non-significant effects were detected, post hoc power analysis was conducted using the statistical software, GPower (http://www.gpower.hhu.de/en.html).

\section{Results}

Inbreeding level had no effect on sperm velocity $\left(F_{3,98}=2.03, \quad \mathrm{P}=0.12 ; \quad\right.$ Fig. 3a $), \quad$ motility $\left(F_{3,98}=0.17\right.$, $\mathbf{P}=0.92 ; \quad$ Fig. $3 b) \quad$ or linearity $\left(F_{3,98}=1.30, \quad \mathbf{P}=0.28\right.$; Fig. 3c). Sperm longevity $\left(\chi^{2}=2.86, \quad\right.$ d.f. $=3, \quad \mathrm{P}=0.41$; Fig. 4a), spermatocrit levels $\left(\chi^{2}=4.60\right.$, d.f. $=3, \quad \mathrm{P}=0.20$; Fig. $4 b)$ and Fulton's $\mathrm{K}\left(\chi^{2}=1.35\right.$, d.f. $=3, \quad \mathrm{P}=0.72$; Fig. 4c) were also not significantly affected by inbreeding level, nor was the sperm head width $\left(F_{3,52}=0.62, \mathrm{P}=0.60\right.$; Fig. 5a), head length $\left(F_{3,52}=0.61, \mathrm{P}=0.60\right.$; Fig. $\left.5 \mathrm{~b}\right)$, or flagellum length $\left(F_{3,52}=0.73, \mathrm{P}=0.54\right.$; Fig. $\left.5 \mathrm{c}\right)$.

Post hoc power analyses revealed that the mean statistical power for the sperm traits measured in this study was 0.82 (velocity $=0.93$; motility $=0.55$; linearity: 0.85 ; longevity: 0.74; spermatocrit: 0.74 ; head width: 0.95 ; head length: 0.95 ; flagellum length: 0.82). Thus, there was adequate power to effectively test the hypotheses that were generated for these analyses.

\section{Discussion}

Our findings did not provide support for the hypothesis that inbreeding affects sperm quality in a captive-bred population of wild-origin lake trout. Instead, we found no apparent inbreeding depression for sperm quality of males
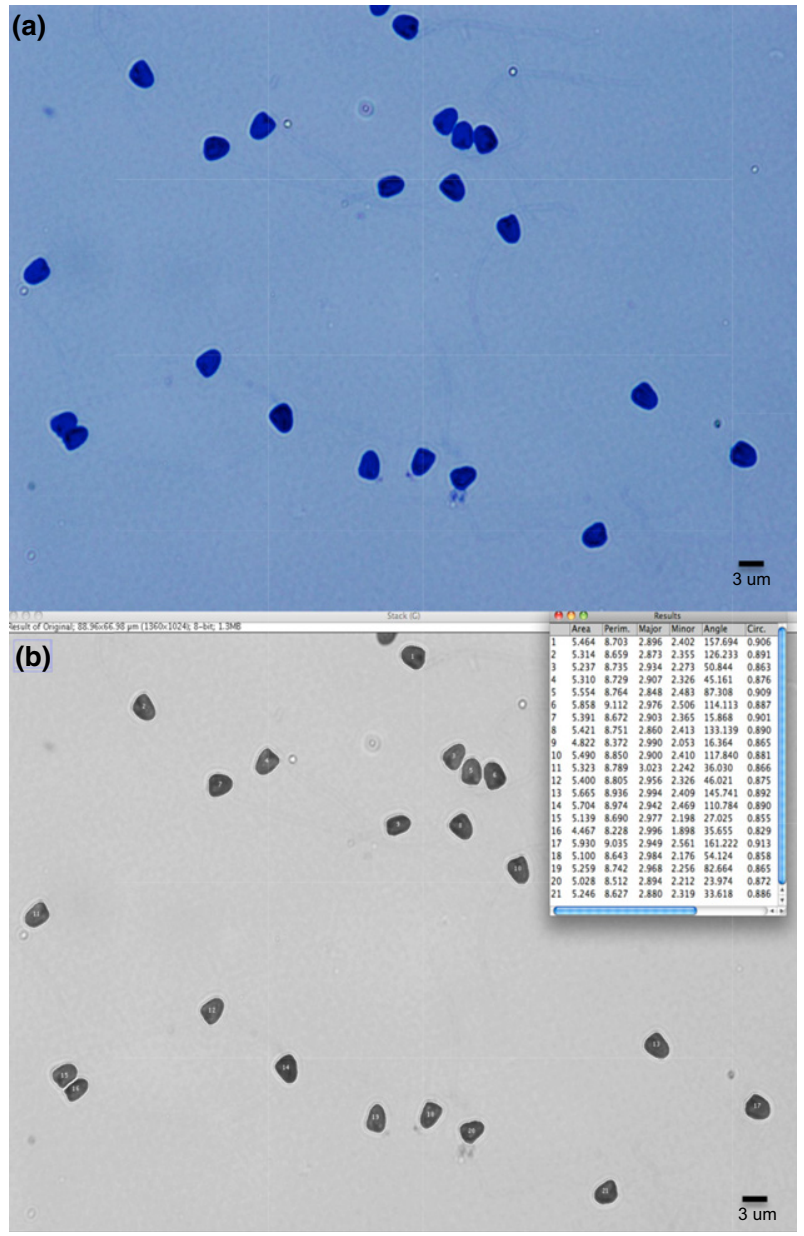

Fig. 2. Digital image of lake trout (Salvelinus namaycush) sperm (100× magnification) (a) before and (b) after running the automated sperm morphology analysis (ASMA) plug-in developed for opensource software (IMAGEJ)

that were progeny of full-sib and maternal and paternal half-sib matings compared to those with unrelated parents. These results do not follow the general pattern reported in the literature of inbreeding causing detrimental effects on sperm quality (Wildt et al., 1987; Barone et al., 1994; Gage et al., 2006). For example, in a recent comparative analysis across 20 endangered mammal species, increased levels of inbreeding inferred from decreased levels of heterozygosity significantly reduced sperm quality traits across both wildcaught and captive populations (Fitzpatrick and Evans, 2009). Here, we discuss possible explanations as to why inbreeding did not lead to inbreeding depression in our study.

It is possible that inbreeding depression may not exist in the studied population. This could be due to several factors including previous purging of deleterious recessive alleles in ancestral wild generations, a lack of inbreeding detection at the gamete level or a lack of inbreeding depression after only one generation of inbreeding. The evolutionary history of lake trout, along with their unique life history strategy may provide support for a lack of detection. Following their 

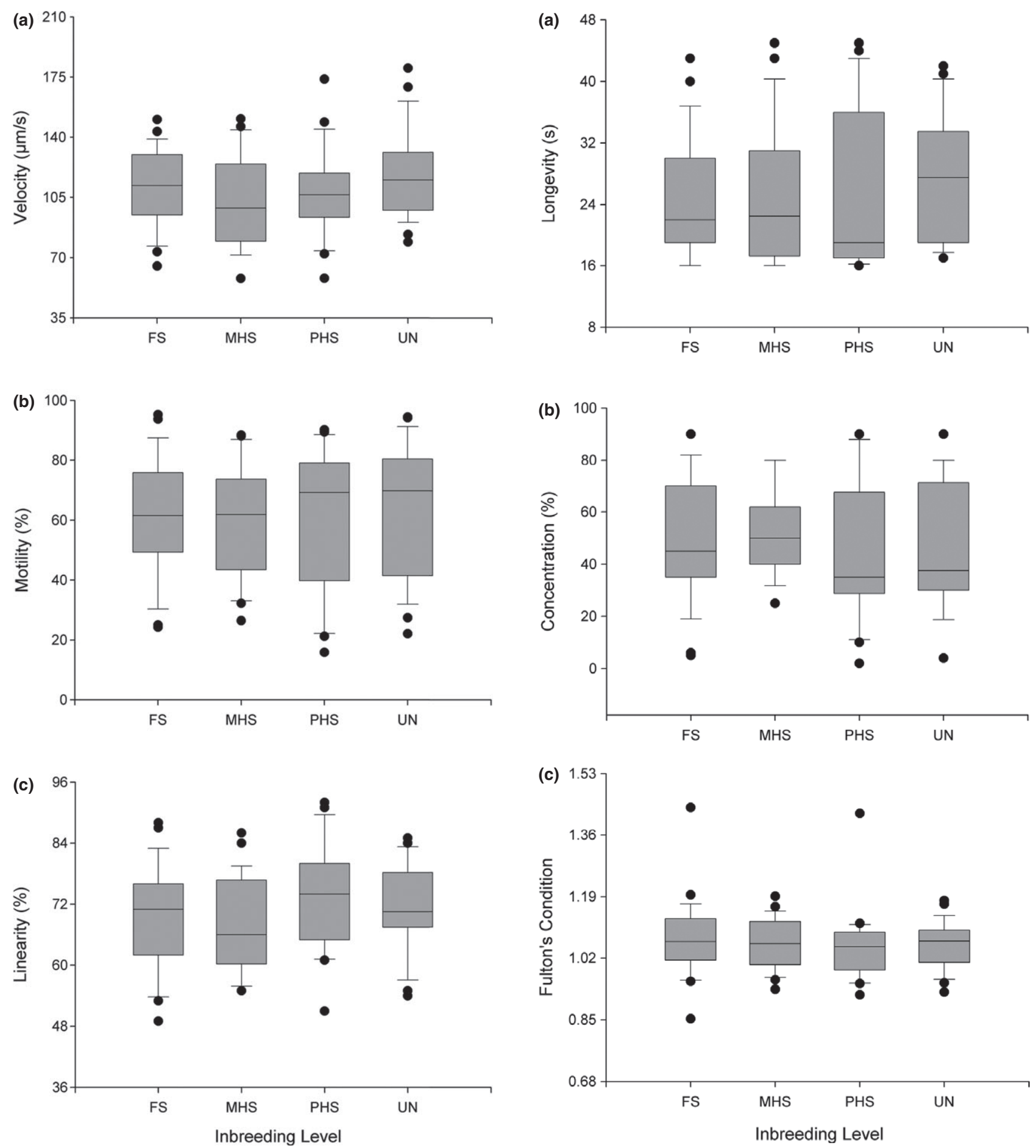

Fig. 3. Observed relationships between (a) sperm velocity, (b) percent motility, and (c) linearity from four mating categories examining inbreeding [full sibling (FS) matings, maternal (MHS) and paternal (PHS) half-sibling matings and unrelated adults (UN)] in captive lake trout (Salvelinus namaycush). Center line in each box $=$ the median. Upper and lower bounds of the box $=$ upper and lower quartiles, respectively; extended lines = maximum and minimum values, excluding outliers (indicated as dots). Raw data are presented

Fig. 4. Observed relationships for (a) sperm longevity, (b) spermatocrit, and (c) Fulton's condition of adult male lake trout (Salvelinus namaycush) from four mating categories examining inbreeding [full sibling (FS) matings, maternal (MHS) and paternal (PHS) half-sibling matings and unrelated adults (UN)]. Center line in each box $=$ the median. Upper and lower bounds of the box $=$ upper and lower quartiles, respectively; extended lines = maximum and minimum values, excluding outliers (indicated as dots). Raw data are presented 

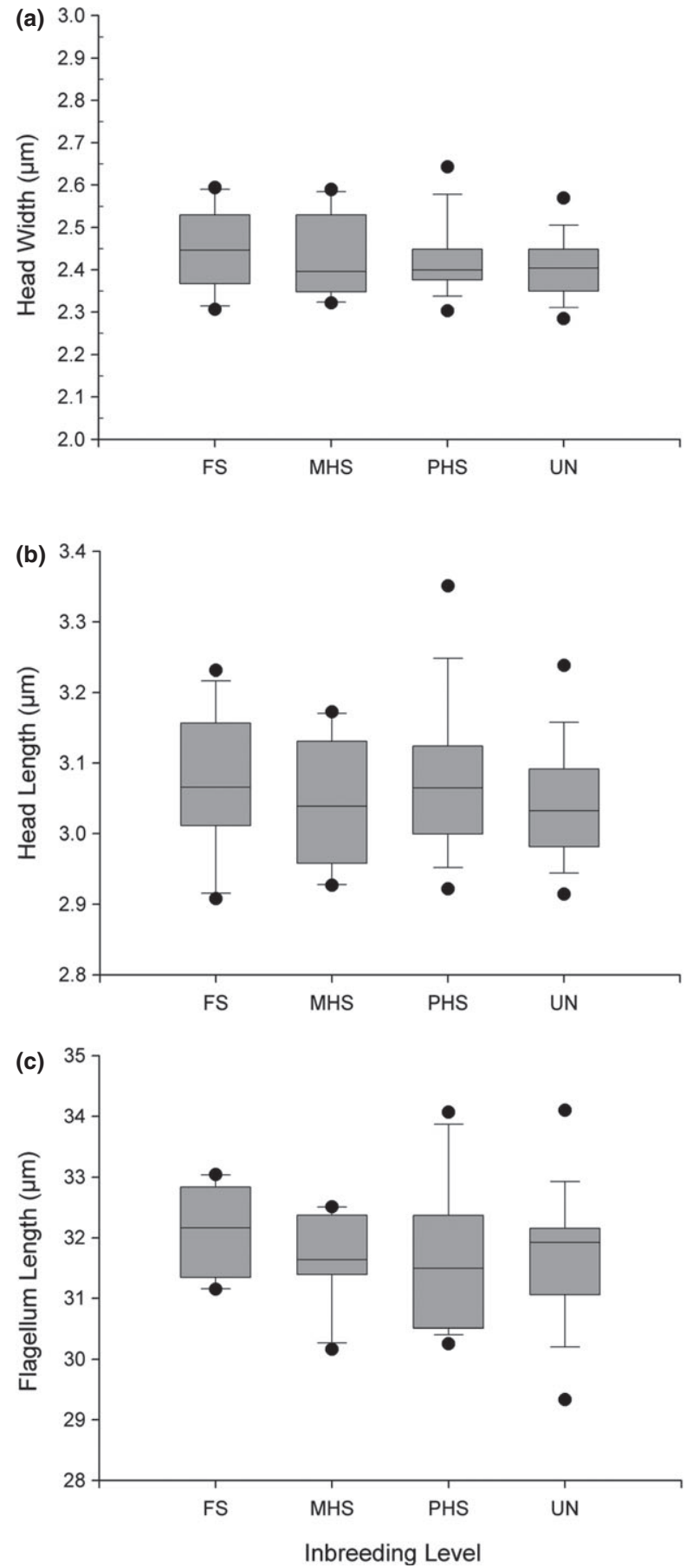

Fig. 5. Observed relationships for (a) sperm head width, (b) sperm head length, and (c) flagellum length from four mating categories examining inbreeding [full sibling matings (FS), maternal (MHS) and paternal (PHS) half-sibling matings and unrelated adults (UN)] in lake trout (Salvelinus namaycush). Center line in each box $=$ the median. Upper and lower bounds of the box = upper and lower quartiles, respectively; extended lines $=$ maximum and minimum values, excluding outliers (indicated as dots). Raw data are presented

post-glacial colonization at the end of the Pleistocene, the majority of lake trout populations inhabit small inland lakes, which act as isolated, closed systems (Wilson and Hebert,
1998). As long-lived, iteroparous top predators in these cold, low productivity lakes, lake trout populations tend to be relatively small, and are correspondingly vulnerable to genetic drift (Wilson and Mandrak, 2004). This life history strategy, along with the lake trout's natural distribution, may have resulted in generations of inbreeding and consequent purging of lethal alleles (Larsen et al., 2011). Purging is a mechanism that reduces the fitness-related losses of inbreeding through the removal of deleterious recessive alleles via natural selection (Thornhill, 1993; Hedrick, 1994). Purging is more likely to occur in small populations with a long history of inbreeding and consequently an accumulation of these lethal alleles (Crnokrak and Barrett, 2002). Once populations have been purged of deleterious recessive alleles, further inbreeding would in theory have no effect on the fitness of the population under the dominance hypothesis of inbreeding depression (Charlesworth and Charlesworth, 1999). Evidence for purging has been shown in both plants and animals (reviewed in Crnokrak and Barrett, 2002). For example, in guppies (Poecilia reticulata), purging was demonstrated in a captive population that had been experimentally reared for 10 generations (Larsen et al., 2011). Inbreeding depression in offspring survival and clutch size increased throughout the first 4-6 generations of inbreeding followed by a recovery in fitness thereafter, despite further generations of inbreeding (Larsen et al., 2011). In a review examining evidence of purging across 25 captive mammal species, a significant trend in purging on neonatal survival was found in 15 out of the 17 species that exhibited inbreeding depression (Ballou, 1997). Although this review failed to provide broad support for purging, it suggested that the effects of inbreeding depression appear to be largely expressed in early life history traits (Ballou, 1997).

In salmonids, there is evidence for inbreeding depression affecting early life history traits such as fry mortality in rainbow trout (Oncorhynchus mykiss) (Kincaid, 1976), while no effect was found for fertility or egg hatching success (Su et al., 1996). Overall, in order to conclude that inbreeding depression in our population had no effect at the gamete level, we would need more information on the extent of population-level inbreeding and drift in ancestral generations of the wild population. Without this, it is difficult to determine whether deleterious recessive alleles were previously lost in our population due to the conditions and assumptions underlying purging as a mechanism for reducing inbreeding depression. An understanding of the ancestral inbreeding history, genetic mechanisms responsible for inbreeding i.e. dominance (necessary for purging) or over-dominance, and strength of selection pressures on deleterious recessive alleles in the wild and in captivity is needed to provide support for purging (Wang et al., 2002).

The apparent lack of inbreeding depression in the study population could also be attributed to the fish being subjected to only one generation of experimental inbreeding. This could lead to underestimates of inbreeding depression on male reproductive potential. In wild salmonids, inbreeding is expected to be a gradual process that takes several generations to demonstrate any negative effects (Wang et al., 2002). In rainbow trout, Su et al. (1996) suggested 
that a lack of detection of inbreeding depression on male fertilization success could be attributed to low levels of inbreeding in their study. Several studies have found evidence for inbreeding depression in species that have experienced multiple generations of inbreeding (Crnokrak and Barrett, 2002). In a study on guppies by Zajitschek et al. (2009), four generations of brother-sister matings $(F=0.59)$ were required to detect any evidence of inbreeding depression on sperm competitiveness. Furthermore, moderately inbred males $(F=0.25)$ showed no reduction in sperm quality. With one generation of inbreeding in our study, male offspring from full sibling matings had an $F$ value of 0.25 , while those from maternal and paternal half-sib matings had $F$ values of 0.125 . Accordingly, our results are consistent with those of Zajitschek et al. (2009), despite the markedly different systems of mating and sexual selection between the two species (Gunn, 1995; Esteve et al., 2008; Zajitschek and Brooks, 2010). Although we did not find evidence for inbreeding depression in our population, we cannot exclude the long-term effects, as successive generations of inbreeding might still result in inbreeding depression (Wang et al., 2002). Soft selection due to captive conditions has been shown to mask the effects of inbreeding depression (Crnokrak and Roff, 1999; Armbruster and Reed, 2005). Differences in the severity of inbreeding depression between captive and wild-caught populations have been documented in a variety of species. Benign living conditions often result in an underestimate of the effects of inbreeding due to a lack of environmental pressure (Crnokrak and Roff, 1999; Hedrick and Kalinowski, 2000; Keller and Waller, 2002; Armbruster and Reed, 2005). These environmental pressures range from unpredictable climate conditions, disease, and resource limitation to the absence of competition for mates (Crnokrak and Roff, 1999; Joron and Brakefield, 2003). Studies that involve the introduction of captive bred individuals into their wild environments often show an increase in the negative effects due to inbreeding. For example, in white-footed mice (Peromyscus leucopus noveboracensis), survivorship rates were lower for inbred individuals reintroduced into the wild, compared to those living under laboratory conditions (Jiménez et al., 1994). In African butterflies (Bicyclus anynana), the effects of inbreeding depression on male mating success were heightened when inbred individuals experienced a natural free flight environment compared to a caged environment (Joron and Brakefield, 2003).

As male-male competition is generally absent in captive populations, negative effects of inbreeding depression are frequently exposed when males directly face competition for mates (Meagher et al., 2000). For example, in Nile tilapia (Oreochromis niloticus), reproductive success of inbred males, defined as the proportion of offspring sired in a single spawning event, was decreased when there were an increased number of males competing for copulations (Fessehaye et al., 2009). Male-male competition at the gamete level has also been shown to increase the effects of inbreeding depression. In the flour beetle (Tribolium castaneum), male fertility was not significantly different between inbred and outbred individuals, however under competition, inbred males were found to suffer from decreased sperm competitiveness (Michalczyk et al., 2010). In guppies (Poecilia reticulata), sperm number was significantly reduced in inbred compared to outbred males, although this effect was not observed under laboratory conditions (Zajitschek and Brooks, 2010). The lake trout in this study had been living in a captive environment for 7 years. Although conditions were semi-natural, with no manipulation of water quality (i.e. water was provided by a natural stream) or temperature, competitive interactions for both resources and mates were absent. Evidence for relaxed selection on lake trout from the same hatchery used in this study has been demonstrated. For example, McDermid et al. (2010) found that wild-caught lake trout out-performed hatchery-reared lake trout in a number of life history traits, including fertilization success. Lake trout in the wild have an opportunity for post-copulatory sexual selection, as multiple males have been observed accompanying a spawning female (Esteve et al., 2008). The potential loss of this selective pressure on sperm competition in males living in captivity may help to explain why both inbred and outbred individuals did not differ in sperm quality metrics.

In summary, sperm quality in lake trout appears to be unaffected by experimental levels of inbreeding in our population. Coefficients of inbreeding depression $(\delta)$ can be used to standardize and compare fitness-related traits affected by inbreeding depression across species. They are calculated as $\delta=1-\left(X_{1} / X_{\mathrm{o}}\right)$, where $X_{1}=$ inbred trait value and $X_{\mathrm{o}}=$ outbred trait value (adapted from Crnokrak and Roff, 1999). In our study, coefficients of inbreeding depression were extremely low compared to those calculated for sperm traits in other species. Our values ranged from 0.12 for sperm longevity to -0.09 for spermatocrit, while $\delta$ values for sperm traits in other studies averaged 0.26 (Wildt et al., 1987; Barone et al., 1994; van Eldik et al., 2006). Therefore, we infer with a high level of certainty that sperm quality of the experimental fish did not suffer from the effects of inbreeding depression. The apparent lack of inbreeding depression for sperm quality may be due to either a true lack of inbreeding depression in the population or a release from sperm competition and sexual selection under hatchery conditions. Our study highlights the importance of the conditions and assumptions needed to detect inbreeding depression at the gamete level, and provides important insights into inbreeding for a hatchery-reared salmonid population.

\section{Acknowledgements}

This research was funded by the Natural Sciences and Engineering Research Council of Canada (NSERC) in the form of Discovery Grants and Research Tools and Instrumentation Grants, as well as grants awarded by the University of Windsor, to T.E.P. Special thanks to Bill Sloan, Scott Ferguson, and Ben Lewis of the Ontario Ministry of Natural Resources and Forestry (OMNRF) for providing invaluable assistance at the OMNR Codrington Fisheries Research Facility. 


\section{References}

Armbruster, P.; Reed, D. H., 2005: Inbreeding depression in benign and stressful environments. Heredity 95, 235-242.

Asa, C.; Miller, P.; Agnew, M.; Rebolledo, J. A. R.; Lindsey, S. L.; Callahan, M.; Bauman, K., 2007: Relationship of inbreeding with sperm quality and reproductive success in Mexican gray wolves. Anim. Conserv. 10, 326-331.

Ballou, J. D., 1997: Ancestral inbreeding only minimally affects inbreeding depression in mammalian populations. J. Hered. 88, $168-177$.

Barone, M. A.; Roelke, M. E.; Howard, J.; Brown, L. J.; Anderson, A. E.; Wildt, D. E., 1994: Reproductive characteristics of male Florida panthers: comparative studies from Florida, Texas, Colorado, Latin America, and North American zoos. J. Mammal. 75, 150-162.

Butts, I. A. E.; Ward, M. A. R.; Litvak, M. K.; Pitcher, T. E.; Alavi, S. M. H.; Trippel, E. A.; Rideout, R. M., 2011: Automated sperm head morphology analyzer for open-source software. Theriogenology 76, 1756-1761.

Butts, I. A. E.; Johnson, K.; Wilson, C. C.; Pitcher, T. E., 2012: Ovarian fluid enhances sperm velocity based on relatedness in lake trout, Salvelinus namaycush. Theriogenology 78, 2105-2109.

Charlesworth, D.; Charlesworth, B., 1999: The genetic basis of inbreeding depression. Genet. Res. 74, 329-340.

Chen, X., 1993: Comparison of inbreeding and outbreeding in hermaphroditic Arianta arbustorum (L.) (land snail). Heredity 71, 456-461.

Crnokrak, P.; Barrett, S. C. H., 2002: Perspective: purging the genetic load: a review of the experimental evidence. Evolution 56, 2347-2358.

Crnokrak, P.; Roff, D. A., 1999: Inbreeding depression in the wild. Heredity 83, 260-270.

van Eldik, P.; van der Waaij, E. H.; Ducro, B.; Kooper, A. W.; Stout, E. A. T.; Colenbrander, B., 2006: Possible negative effects of inbreeding on semen quality in Shetland pony stallions. Theriogenology 65, 1159-1170.

Esteve, M.; McLennan, D. A.; Gunn, J. M., 2008: Lake trout (Salvelinus namaycush) spawning behaviour: the evolution of a new female strategy. Environ. Biol. Fishes 83, 69-76.

Fessehaye, Y.; Bovenhuis, H.; Rezk, M. A.; Crooijmans, R.; van Arendonk, J. A. M.; Komen, H., 2009: Effects of relatedness and inbreeding on reproductive success of Nile tilapia (Oreochromis niloticus). Aquaculture 294, 180-186.

Fitzpatrick, J. L.; Evans, J. P., 2009: Reduced heterozygosity impairs sperm quality in endangered mammals. Biol. Lett. 5, 320-323.

Gage, M. J. G.; Macfarlane, C. P.; Yeates, S.; Ward, R. G.; Searle, J. B.; Parker, G. A., 2004: Spermatozoal traits and sperm competition in Atlantic salmon: relative sperm velocity is the primary determinant of fertilization success. Curr. Biol. 14, 44-47.

Gage, M. J. G.; Surridge, A. K.; Tomkins, J. L.; Green, E.; Wiskin, L.; Bell, D. J.; Hewitt, G. M., 2006: Reduced heterozygosity depresses sperm quality in wild rabbits, Oryctolagus cuniculus. Curr. Biol. 16, 612-617.

Galvano, P. M.; Johnson, K.; Wilson, C. C.; Pitcher, T. E.; Butts, I. A. E., 2013: Ovarian fluid influences sperm performance in lake trout, Salvelinus namaycush. Reprod. Biol. 13, 172-175.

Grant, P. R.; Grant, R., 1995: The founding of a new population of Darwin's finches. Evolution 49, 229-240.

Guinand, B.; Scribner, K. T.; Page, K. S.; Burnham-Curtis, M. K., 2003: Genetic variation over space and time: analyses of extinct and remnant lake trout populations in the upper Great Lakes. Proc. R. Soc. B 270, 425-433.

Gunn, J. M., 1995: Spawning behavior of lake trout: effects on colonization ability. J. Great Lakes Res. 21(Suppl. 1), 323-329.

Hedrick, P. W., 1994: Purging inbreeding depression and the probability of extinction: full-sib mating. Heredity 73, 363-372.

Hedrick, P. W.; Kalinowski, S. T., 2000: Inbreeding depression in conservation biology. Annu. Rev. Ecol. Evol. Syst. 31, 139-162.

Hoysak, D. J.; Liley, R. N., 2001: Fertilization dynamics in sockeye salmon and a comparison of sperm from alternative male phenotypes. J. Fish Biol. 58, 1286-1300.
Jiménez, J. A.; Hughes, K. A.; Alaks, G.; Graham, L.; Lacy, R. C., 1994: An experimental study of inbreeding depression in a natural habitat. Science 266, 271-273.

Johnson, K.; Butts, I. A. E.; Wilson, C. C.; Pitcher, T. E., 2013: Sperm quality of hatchery-reared lake trout throughout the spawning season. N. Am. J. Aquac. 75, 102-108.

Johnston, M. O., 1992: Effects of cross and self-fertilization on progeny fitness in Lobelia cardinalis and L. siphilitica. Evolution 46, 688-702.

Joron, M.; Brakefield, P. M., 2003: Captivity masks inbreeding effects on male mating success in butterflies. Nature $\mathbf{4 2 4}$, 191-194.

Keller, L. F.; Waller, D. M., 2002: Inbreeding effects in wild populations. Trends Ecol. Evol. 17, 230-241.

Kincaid, H. L., 1976: Inbreeding in rainbow trout (Salmo gairdneri). T. Am. Fish. Soc. 33, 2420-2426.

Lacy, R. C.; Petric, A.; Warneke, M., 1993: Inbreeding and outbreeding in captive populations of wild animals. In: The Natural History of Inbreeding and Outbreeding: theoretical and Empirical Perspectives. N. W. Thornhill (Ed.) University of Chicago Press, Chicago, pp. 352-374.

Larsen, L.-K.; Pélabon, C.; Bolstad, G. H.; Viken, A.; Fleming, I. A.; Rosenqvist, G., 2011: Temporal change in inbreeding depression in life-history traits in captive populations of guppy (Poecilia reticulata): evidence for purging? J. Evolution. Biol. 24, 823-834.

Malo, A. F.; Martinez-Pastor, F.; Alaks, G.; Dubach, J.; Lacy, R. C., 2010: Effects of genetic captive-breeding protocols on sperm quality and fertility in the white-footed mouse. Biol. Reprod. 85, 540-548.

McDermid, J. L.; Sloan, W. N.; Wilson, C. C.; Shuter, B. J., 2010. Early life history variation among hatchery- and wild-origin lake trout reared in a hatchery environment. Trans. Am. Fish. Soc. 139, 21-28.

Meagher, S.; Penn, D. J.; Potts, W. K., 2000: Male-male competition magnifies inbreeding depression in wild house mice. Proc. Natl Acad. Sci. 97, 3324-3329.

Michalczyk, L.; Martin, O. Y.; Millard, A. L.; Emerson, B. C.; Gage, M. J. G., 2010: Inbreeding depresses sperm competitiveness, but not fertilization or mating success in male Tribolium castaneum. Proc. R. Soc. B 277, 3483-3491.

Miller, L. M.; Kapuscinski, A. R., 2003: Genetic guidelines for hatchery supplementation programs. In: Population Genetics: Principles and Practices for Fisheries Scientists. E. M. Hallerman (Ed.). American Fisheries Society, Bethesda, pp. 329-355.

Pitcher, T. E.; Doucet, S. M.; Beausoleil, J.; Hanley, D., 2009: Secondary sexual characters and sperm traits in coho salmon (Oncorhynchus kisutch). J. Fish Biol. 74, 1450-1461.

Rijks, J. M.; Hoffman, J. I.; Kuiken, T.; Osterhaus, A. D. M. E.; Amos, W., 2008: Heterozygosity and lungworm burden in harbour seals (Phoca vitulina). Heredity 100, 587-593.

Ruiz-Lopez, M. J.; Evenson, D. P.; Espeso, G.; Gomendio, M.; Roldan, E. R. S., 2010: High levels of DNA fragmentation in spermatozoa are associated with inbreeding and poor sperm quality in endangered ungulates. Biol. Reprod. 83, 332-338.

Saccheri, I. J.; Lloyd, H. D.; Helyar, S. J.; Brakefield, P. M., 2005: Inbreeding uncovers fundamental differences in the genetic load affecting male and female fertility in a butterfly. Proc. R. Soc. B 272, 39-46.

Selgeby, J. H.; Eschenroder, R. L.; Krueger, C. C.; Marsden, J. E.; Pycha, R. L. (Eds.), 1995: International conference on restoration of lake trout in the Laurentian Great Lakes. J. Great Lakes Res. 21(Suppl. 1), 563 pp.

Stearns, S. C., 1992: The Evolution of Life Histories. Oxford University Press, Oxford.

Su, G. S.; Liljedahl, L. E.; Gall, G. A. E., 1996: Effects of inbreeding on growth and reproductive traits in rainbow trout (Oncorhynchus mykiss). Aquaculture 142, 139-148.

Thornhill, N. W., 1993: The Natural History of Inbreeding and Outbreeding: Theoretical and Empirical Perspectives. University of Chicago Press, Chicago. 
Tuset, V. M.; Dietrich, G. J.; Wojtczak, M.; Słowińska, M.; de Monserrat, J.; Ciereszko, A., 2008: Relationships between morphology, motility and fertilization capacity in rainbow trout (Oncorhynchus mykiss) spermatozoa. J. Appl. Ichthyol. 24, 393397.

Walters, C. J.; Steer, G.; Spangler, G., 1980: Responses of lake trout (Salvelinus namaycush) to harvesting, stocking, and lamprey reduction. Can. J. Fish Aquat. Sci. 37, 2133-2145.

Wang, S.; Hard, J. J.; Utter, J., 2002: Salmonid inbreeding: a review. Rev. Fish Biol. Fish. 11, 301-319.

Wildt, D. E.; Bush, M.; Goodrowe, K. L.; Packer, C.; Pusey, A. E.; Brown, J. L.; Joslin, P.; O'Brien, S. J., 1987: Reproductive and genetic consequences of founding isolated lion populations. Nature 329, 328-331.

Wilson, C. C.; Hebert, P. D. N., 1998: Phylogeography and postglacial dispersal of lake trout (Salvelinus namaycush) in North America. Can. J. Fish Aquat. Sci. 55, 1010-1024.

Wilson, C.C.; Mandrak , N., 2004: History and evolution of lake trout in Shield lakes: past and future challenges. In: Boreal Shield Watersheds: Lake Trout Ecosystems in a Changing Envi- ronment. J. Gunn, R. Steedman, R. Ryder (Eds). CRC Press, Boca Raton, FL. pp. 21-35.

Wright, S., 1977: Evolution and the Genetics of Populations, Experimental Results and Evolutionary Deductions, Vol. 3. University of Chicago Press, Chicago.

Yeates, S.; Searle, J.; Ward, G.; Gage, M. J. G., 2007: A two-second delay confers first-male fertilization precedence within in vitro sperm competition experiments in Atlantic salmon. J. Fish Biol 70, 318-322.

Zajitschek, S. R. K.; Brooks, R. C., 2010: Inbreeding depression in male traits and preference for outbred males in Poecilia reticulata. Behav. Ecol. 21, 884-891.

Zajitschek, S. R. K.; Lindholm, A. K.; Evans, J. P.; Brooks, R. C., 2009: Experimental evidence that high levels of inbreeding depress sperm competitiveness. J. Evol. Biol. 22, 1338-1345.

Author's address: Trevor E. Pitcher, Department of Biological Sciences \& Great Lakes Institute for Environmental Research, University of Windsor, 401 Sunset Avenue, Windsor, ON N9B 3P4, Canada. E-mail: tpitcher@uwindsor.ca 